\title{
CARE AT A DISTANGE ADAPTING DURING THE PANDEMIC
}

THE COVID-19 PANDEMIC HAS TESTED HEALTHCARE FACILITIES TO THEIR LIMITS. ONE EFFECT HAS BEEN A TRANSITION TOWARDS REMOTE CONSULTATIONS, WHICH RAISES UNIQUE CHALLENGES FOR ACCURATE DIAGNOSES. BASED AT THE UNIVERSITY OF OXFORD'S MEDICAL SCIENCES DIVISION, IN THE UK, PROFESSOR TRISH GREENHALGH AND PHD STUDENT LAIBA HUSAIN HAVE BEEN DEVELOPING METHODS TO ENSURE REMOTE CARE IS AS EFFECTIVE AS POSSIBLE

\section{GLOSSARY}

BAME - Black, Asian, and minority ethnic groups

MPH - Master's of Public Health

QUALITATIVE DATA - non-numerical data - for example people's descriptions of their feelings

"Before the pandemic, very few people had phone or video consultations with their GP," says Professor Trish Greenhalgh. "When the pandemic broke out, the high infection risk meant that GPs found themselves carrying out many more remote consultations." Trish is Professor of Primary Care Health Sciences at the University of Oxford's Medical Sciences Division, and has been involved in both the academic and practical sides of healthcare. She has had her work cut out during the pandemic, helping the health service adapt to a rapidly changing situation by researching how to make their Remote-by-Default Care system as effective as possible.

\section{REMOTE CONSULTATIONS}

"There are a number of challenges to remote consultations," says Trish. "Firstly, they rely upon technology that may not work
QUANTITATIVE DATA - numerical data, typically a measurement

REMOTE-BY-DEFAULT CARE - a form of medical care where the baseline point of contact is via phone, video or web portal

$100 \%$ of the time, depending on internet, signal, and the devices that patients and clinicians have available. It is also an unfamiliar format for many, leading to frustrations, misunderstandings and even giving up. Perhaps most importantly, it is impossible to undertake a full examination remotely, including for possible symptoms of COVID-19." A physical examination for COVID-19 would involve taking a patient's temperature, pulse and blood pressure, looking into their mouth and throat, listening to their lungs using a stethoscope, and using an oximeter to estimate blood oxygen levels. "None of these things can be done easily via a remote connection," says Trish.

This shift to remote consultations has had profound impacts for many patients, both those suffering from COVID-19 and from other illnesses. This was especially apparent during the first wave of infections when COVID-19 symptoms were less well understood. "Some people who were very sick were misdiagnosed as only moderately sick, and some people who were only moderately sick were misdiagnosed as very sick - and then sent to hospital where they were potentially exposed to COVID-19 infection from others," says Trish. "We don't know how many people were affected in these ways, but we do know the shortcomings of remote consultation had a role to play."

\section{THE EARLY WARNING SCORE}

In a study called RECAP (Remote COVID-19 Assessment in Primary Care), Trish has worked with other researchers to develop an 'early warning score' - a series of questions that GPs can ask to accurately identify seriously unwell patients and fast-track them for urgent assessment. "Questions cover the history of illness and symptoms, current symptoms, and some elements of physical examination or home tests that could be undertaken by the patient or someone else in the household," says Trish. "Where kit wasn't available, we investigated whether self-reported answers would suffice - for instance, could a description of 'feeling hot and shivery' replace a thermometer reading to confirm a fever?"

The score used the latest research into the virus to work out what symptoms were most concerning. "We read a lot of scientific papers 


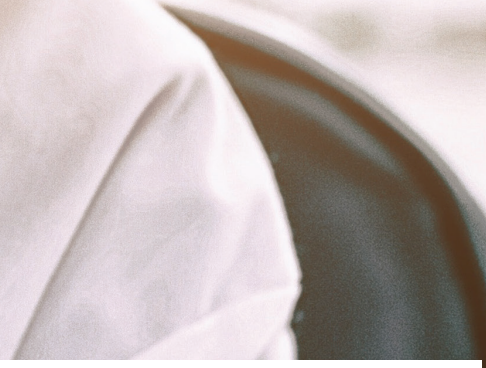

that had been rapidly published in the early days of the pandemic to learn as much as we could," says Trish. "For example, loss of smell is a strong predictor of COVID-19 infection, but is just as likely to happen in mild cases as serious cases.

On the other hand, both aching muscles and drowsiness are seen much more commonly in serious cases."

Trish's team also interviewed over 100 people who had experienced COVID-19 infections, both mild and severe, to learn about their experiences of remote consultation. This included recounting what doctors had asked them, and also whether they felt their concerns over symptoms had been taken seriously. "We also interviewed about 70 frontline clinicians to get their experiences of performing remote consultations," says Trish. "They helped us draft a list of severity indicators, which we refined through online discussion. After a few weeks, we had produced a 10 -item score which we then went on to validate."

\section{NUMBERS AND WORDS}

One main impact of shifting to remote consultation is that quantitative data - such as readings from thermometers or oximeters became a lot more difficult to collect. Instead, GPs relied more on patients' subjective accounts of their symptoms. Qualitative data is often treated with mistrust in the hard sciences, but Trish wanted to see whether particular words and expressions might accurately distinguish between mild and severe cases.

"We found that questions such as 'How breathless are you feeling compared to yesterday?' seemed to be as accurate - and possibly more accurate - in identifying serious illness than so-called 'objective' measurements such as respiratory rate," she says. "This was because open-ended questions drew rich descriptions of how the illness was affecting people, and experienced doctors could identify 'red flags' within these descriptions that would be missed by one-off measurements." Her team drew from a wide pool of experience to ensure questions were worded in such a way that they could be understood by people of different ages and ethnic backgrounds.

However, while this qualitative data is undeniably useful for individual diagnoses, it is still difficult to process on a large scale. Trish's team had to find a way to convert it to quantitative data so it could be a useful part of national or international datasets. "Each response to our 10-item score is coded," says Trish. "For instance, responses to do with change in breathlessness may be categorised as 'same or better than yesterday', 'worse than yesterday', or 'significant deterioration in the last hour', each of which is assigned a different code."

\section{DATA LINKAGE}

Once the responses of several thousand patients have been coded in this way, they start to form useful datasets for spotting trends. "We use data linkage to see how these codes correlate with key outcomes we're interested in: hospital admission, intensive care unit admission, and death within 28 days," says Trish.

This is not necessarily a straightforward task, given that personal data is dispersed around several different systems. "GP medical records contain data on consultations and medication, but they are separate from hospital records," says Trish.

"Similarly, deaths may be recorded separately if they don't take place in a hospital." Fortunately, these datasets can all be linked, for example by a patient's NHS number, so that if the same NHS number can be identified in the different datasets, then the records should link to the same person.

However, there is another catch. "Medical information is highly sensitive, and is rightly covered by data protection laws," says Trish. "This means that compiling the datasets involves a lot of legal permissions, and special care to ensure no patient within the dataset can be identified with their name. But once these hurdles are cleared, we can get a clearer idea of how particular

\section{BEYOND THE PANDEMIC}

What comes next for healthcare in the UK? symptoms are linked to outcomes."

,




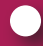 ABOUT ACADEMIC PRIMARY HEALTH CARE}

Primary health care covers the first point of contact for healthcare. GPs are the best-known example of this, helping to diagnose patients and propose solutions such as prescriptions or referral to hospital departments. Academic primary health care involves studying how to make this process as effective as possible, using evidence from research to propose changes to the ways that primary health care is undertaken. Trish explains more about the field and her role.

Almost all medically-qualified professors split their time between working in the NHS and in their academic role. I used to work two days a week as a GP and three in the university, though I later cut down to one day a week as a GP as my university job was very demanding. A few years ago, I dropped the clinical aspects of my job entirely, as my university research and teaching responsibilities expanded.

People often debate whether medicine is a science or an art, but I believe it's best defined as a professional practice - just like law or social work. Like any professional practice, our duty is to do what's best for the patient or client, while maintaining confidentiality and drawing on science and other relevant evidence when needed. So, for instance, for an acutely unwell patient, science is needed to diagnose and treat the ailment, but compassion and respect for autonomy are needed to ensure the patient receives the best care they can. There is no conflict here - both science and art are equally vital.

If you have a high level of scientific curiosity and enjoy discovering answers, you may be cut out for research. While reading this article, did you find the ideas of diagnostic tools and data linkage interesting? Can you come up with any of your own ideas for improving assessment of patients, or consider any other scientific questions that could be answered through data linkage? If so, academic primary care could be for you.
GXPLORE A CAREF IN ACADEMIC PRIMARY HEALTH CARE

- Medicine is the most obvious subject to study at university to pursue a career in academic primary health care. A good understanding of the health service and the science behind it will be necessary for such a career.

- Relevant work experience is often essential when applying to a medicinebased degree. The Medical Schools Council has some useful tips for getting started in this space: www.medschools.ac.uk/studyingmedicine/making-an-application/ work-experience

- Salaries for careers in medicine can vary substantially but are generally quite well-paid. The British Medical Association has more information: www.bma.org.uk/pay-and-contracts/ pay/other-doctors-pay-scales/ medical-academics-pay-scales

\section{PATHWJY FROM SGHOOL TO ACADEMIC PRIMARY CARE}

Trish says to see what particular medical schools require at A-Level (typically biology, chemistry, and maths and/or physics). She emphasises the importance of getting involved in research projects once at university - she says academic recruiters pay more attention to these research experiences than to the specific choice of A-level subjects. Once you have your medical degree, you'll need to do a $\mathrm{PhD}$ before being ready to lead your own research study.

These can be done part-time while also pursuing your clinical training.

For those who prefer not to train as a doctor first, Laiba (Trish's research assistant who you will meet on the following pages) recommends an undergraduate degree in one of the human sciences (such as psychology or sociology) and then seeking university master's courses with a clear research component where you would learn qualitative methods (such as how to conduct interviews with people) and quantitative research methods (such as how to analyse datasets using statistics).

Laiba did a psychology and neuroscience bachelor's and a public health master's. Her route illustrates how people without a medical degree can build a career in a health-related subject with a view to going on to lead research in that field. 


\section{HOW DID TRISH BECOME A GP AND PRIMARY HEALTH CARE ACADEMIC?}

WHAT WERE YOUR INTERESTS WHEN YOU WERE GROWING UP?

I did a lot of sport. I swam, played hockey, and ran cross-country. I was also in the $\mathrm{St}$ John Ambulance Brigade and the Royal Life Saving Society, which were excellent preparation for medical school. I still love sport, and after university I was briefly in the UK Ironman triathlon team. Sport was a great relaxation for me when studying hard for exams, which you have to do to succeed in medicine. It also taught me self-discipline and the value of teamwork. You don't have to be good at sport to get into medical school - other leisure activities which prepare you well include music, drama or being on a school council.

\section{WHAT INSPIRED YOU TO BECOME} A GP?

A patient. I initially trained as a hospital doctor specialising in diabetes. One patient, who I had helped with some tough challenges in her life, turned to me and said, "I wish you were my GP." That made me realise that I wanted to care for all aspects of people's health, not just diabetes.

\section{HAVE YOU HAD ANY EUREKA} MOMENTS IN YOUR CAREER?

There have been few eureka moments. It's a bit like motherhood - on a day-to-day basis it feels like slow progress, but when you look back at what you've created, be it a well-adjusted child or a life-saving research programme, you see it's worth the grind.
HOW DO YOU SWITCH OFF FROM YOUR WORK?

I never go a day without exercise. I begin each day at 6 am with 40 minutes of yoga and stretching. I am also a wild swimmer, plunging into the Thames all year round. With a husband and two grown-up children, I make sure I enjoy family life, as well as academia and medicine!

\section{WHAT ARE YOUR PROUDEST CAREER} ACHIEVEMENTS SO FAR?

In 2001, I received an OBE for Services to Medicine from the Queen. I also think I played a part in persuading UK policymakers to introduce mask mandates during the pandemic, which have probably saved many lives.

\section{TRISH'S TOP TIPS}

01 Get involved in a small research project as soon as you can when you start university. Look out for opportunities!

02 Be curious. Science is not all about taking measurements and analysing data. It's also about having the imagination to work out what to measure and what to analyse, and why.

03 If you are seriously considering a career in research, choose a research-oriented university. This could be any of the 'golden triangle' (Cambridge, Oxford, and London), but a lot of excellent research is also happening at other universities, such as Edinburgh, Manchester, Leeds Sheffield, Birmingham and Newcastle. Ask about research opportunities at your interview. 


\title{
LAIBA HUSAIK
}

\author{
LAIBA HUSAIN IS A PHD STUDENT WHO WORKS CLOSELY \\ WITH TRISH. SHE EXPLAINS HER ROLE IN THE REMOTE-BY- \\ DEFAULT CARE PROJECT, HOW IT TIES IN WITH HER PHD, \\ AND THE PATH SHE HAS TAKEN TO REACH THIS POINT.
}

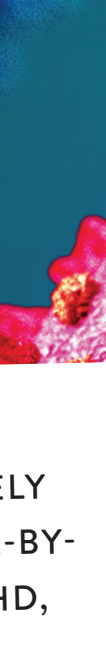

\section{WHAT IS YOUR ROLE IN THIS}

\section{RESEARCH PROJECT?}

I've been able to take on a lot of roles as research assistant to Professor Trish Greenhalgh. I have conducted interviews and facilitated virtual discussion groups with people who have had long COVID, and led a design project to create resources for patients. I have also been involved with the RECAP (Remote COVID-19 Assessment in Primary Care) study to develop the tool for identification of COVID-19 patients who are at higher risk of poor outcome.

\section{WHAT LED YOU TO THIS PROJECT?}

Before moving to the UK, I was involved in community engagement projects with incoming Syrian refugees back home in Michigan, USA. I really enjoyed this work and was passionate about continuing it when I moved. Once I had started my Fulbright Scholarship here in the UK, I began research into qualitatively exploring trust in healthcare within UK refugee and migrant populations. I realised how valuable it is to work with vulnerable populations on their healthcare needs, especially if research can help those populations who don't have a voice of their own. After graduating, I worked with an autism charity to research ways of using video technology to diagnose autism. When I began working with Trish on the Remote-by-Default Care project, I was able to further explore this interaction of vulnerable populations and digital inclusion, and here we are now!

\section{WHAT DOES YOUR PHD COVER?}

My research question is: What are the barriers to remote consultations for those with low uptake (especially BAME, lowincome, and older people), and how can we work in partnership with patients and the public to help overcome these? I aim to identify, and develop methods to overcome, patient-level inequities in scaling up virtual consultations, focusing on those groups who have shown the most limited uptake of video consultation services.

\section{HOW DOES YOUR PHD TIE IN TO THE REMOTE-BY-DEFAULT CARE PROJECT?}

The pandemic has shown the usefulness of remote consultations to deliver care, but for them to be truly effective, they need to be a routinely used part of our health system. Remote consultations can be very different to in-person consultations, so there is a need to monitor and support adoption of this technology by patients as part of the implementation process. It is worth noting that COVID-19 has had a disproportionate impact on the elderly, the poor, and those from BAME groups. Ironically, these are also the groups who, overall, are least able to effectively access digital consultations. My PhD aims to produce a rich and detailed understanding of the barriers they face, and how they can be overcome, to ensure effective and equitable care for all.

\section{WHAT CHALLENGES DOES THIS RESEARCH POSE FOR YOU?}

We've been organising structured sessions to address the challenges faced by clinicians and service providers when using video consultation platforms. These platforms have been successful within small-scale pilot projects, but the routine use of video consultations nationwide remains limited. This is because they bring in major changes to the nature of care, such as changes to workflows for clinicians and new barriers for patients, especially those with lower digital capabilities. These sessions have given me an in-depth understanding of the challenges involved in scaling up, and the barriers to patient adoption.

\section{HOW HAVE YOU FOUND}

BEGINNING A PHD IN A

\section{PANDEMIC?}

Being a PhD student involves a lot of independent study and work, and this has been amplified by the pandemic. I've learned to adapt and find it really helpful to maintain a routine and study schedule at home. I have my own study space and schedule breaks to get some exercise and fresh air, which makes all the difference. 


\section{ABOUT PUBLIC HEALTH RESEARCH}

Public health research covers anything that affects the health of populations. This can be purely biological, such as genetics; environmental, such as air quality; or social, such as equity and accessibility. Research findings can be used to provide evidence for changes to policy, to improve population health and well-being. Laiba explains more.

A career in research can be challenging. We are constantly made to question our assumptions and produce new outputs. However, the collaborative nature of research also broadens your mind, connecting you to people who help your research develop in unforeseen ways. A research career is quite holistic, involving adaptation, curiosity, and teamwork skills.
Research is also a rewarding career, as you are able to try out new ideas, experiment with cutting-edge technology, and take part in engaging discussions. I am proud to be part of a network that is working to improve people's lives.

\section{I recommend starting early to} prepare for a career in public health research. Look for local volunteer work, involvement in non-profit organisations, and public health internships. This will give you a better sense of what a career in the field could entail. Some university courses offer a semester abroad in a global health programme, which can be a great way to gain an international perspective.

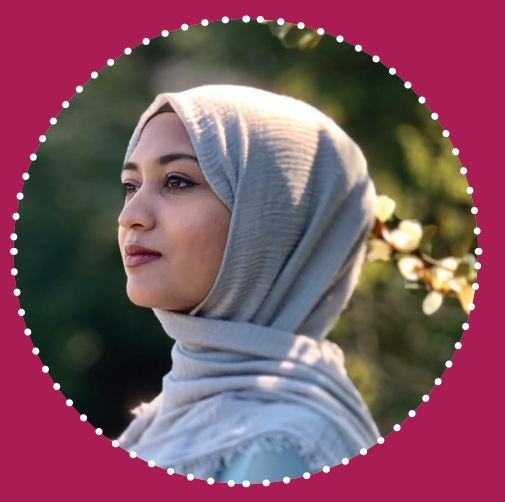

\section{LAIBA HUSAIN}

PhD Student and Research Assistant, Nuffield Department of Primary Care Health Services, Medical Sciences Division, University of Oxford, UK

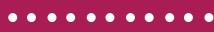

\section{FIELD OF RESEARCH}

Public Health, Qualitative Research

\section{RESEARCH PROJECT}

Understanding barriers to remote consultations for vulnerable groups, and

how they can be overcome

\section{FUNDERS}

THIS Institute (The Healthcare Improvement Studies Institute), National Institute for Health Research

\section{HOW DID LAIBA BECOME A PUBLIC HEALTH RESEARCHER?}

WHAT WERE YOUR INTERESTS WHEN YOU WERE GROWING UP?

I loved to read! I still try to find time to read now. When I was younger, I would practically live in the library.

WHAT INSPIRED YOU TO BECOME A RESEARCHER?

My mentor (and now PhD supervisor) Trish Greenhalgh has been my main inspiration. She is absolutely brilliant and watching her in action daily has exemplified what it means to be a successful researcher and an amazing woman. I can only dream of being at her level one day!

\section{WHAT ATTRIBUTES HELP MAKE YOU} SUCCESSFUL AS A RESEARCHER? I think my curious nature and focused work ethic have played a big part. Resourcefulness, tenacity and strong attention to detail are also worthwhile traits.

\section{HOW DO YOU SWITCH OFF FROM} YOUR WORK?

I love art - I paint, crochet, and do design work in my free time. This creative outlet helps me relax and unwind.

\section{WHAT ARE YOUR PROUDEST CAREER} ACHIEVEMENTS SO FAR?

I was proud to receive the THIS Institute Fellowship Award to do my PhD at Oxford! Another great moment was being awarded the US-UK Fulbright Scholar Award to conduct public health research and do my MPH abroad. Also up there is when I gave a talk on BBC Four Thought on the empowerment of Muslim women.
WHAT ARE YOUR GOALS AFTER YOU HAVE COMPLETED YOUR PHD?

I plan to do a post-doctoral fellowship and ultimately work my way up to professorship.

\section{LAIBASS TOP TIP}

Always be open to new opportunities! Your university years will be a great time to step outside of your comfort zone and explore various fields outside of the classroom setting. Become a student researcher, get involved in student-run campus organisations, and don't be afraid to ask professors and lecturers for advice. 